\title{
Painful neuropathy: comparative observational analysis of safety profile of pregabalin and amitriptyline
}

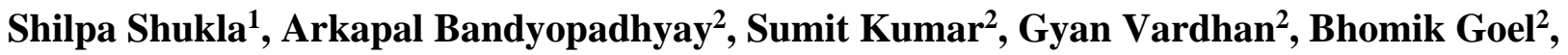 \\ Chahat Choudhary ${ }^{2}$, Ravi Kant ${ }^{3}$, Puneet Dhamija ${ }^{2 *}$
}

${ }^{1}$ Uttarakhand Technical University, Dehradun, Uttarakhand, India

${ }^{2}$ Department of Pharmacology, All India Institute of Medical Sciences, Rishikesh, Uttarakhand, India

${ }^{3}$ Department of Medicine, All India Institute of Medical Sciences, Rishikesh, Uttarakhand, India

Received: 20 May 2021

Revised: 12 June 2021

Accepted: 14 June 2021

*Correspondence:

Dr. Puneet Dhamija,

Email: drpdhamija@gmail.com

Copyright: $\odot$ the author(s), publisher and licensee Medip Academy. This is an open-access article distributed under the terms of the Creative Commons Attribution Non-Commercial License, which permits unrestricted non-commercial use, distribution, and reproduction in any medium, provided the original work is properly cited.

\begin{abstract}
Background: Chronic neuropathic pain, caused by a lesion or disease of the somatosensory nervous system is a common debilitating condition in clinical practice. Pregabalin and Amitriptyline are most commonly used drugs for its management. The aim of the study was to study the safety of Pregabalin and Amitriptyline in chronic neuropathic pain. Methods: Prospective observational study at Department of Medicine and Orthopaedics at All India Institute of Medical Sciences, Rishikesh. Newly diagnosed patients of neuropathic pain who were prescribed either Pregabalin or Amitriptyline were included in the study. Patients were followed up telephonically or during routine visits for a period of 3 months after initiation of any of these drugs. Appropriate measures of central tendency were used to describe demographic and clinical parameters and Correlation test was used between different variables and occurrence of adverse drug reactions.

Results: 317 patients were prescribed these drugs. A total of 276 ADRs were observed (128 with Pregabalin and 148 with Amitriptyline). Central nervous system symptoms like sedation and dizziness were most commonly present in both the groups. Diabetes mellitus (47.1\%) was most common etiology for neuropathic pain. Causality assessment showed probable association with Amitriptyline $(\mathrm{n}=140)$ and Pregabalin $(\mathrm{n}=118)$. Majority of ADRs with Amitriptyline group $(49.32 \%)$ were moderate in severity whereas it was mild with Pregabalin $(59.7 \%)$. A weak positive correlation $(\mathrm{R}=0.273)$ was seen with number of ADRs occurrence and total drug exposure in patients taking Pregabalin whereas a weak negative correlation $(\mathrm{R}=-0.623)$ was seen in Amitriptyline treated group.

Conclusions: Safety profile of Pregabalin was better than Amitriptyline in the present study. The study findings must be replicated in larger patient population and for a prolonged duration for better understanding of the pattern of adverse drug reactions.
\end{abstract}

Keywords: Painful neuropathy, Amitriptyline, Pregabalin

\section{INTRODUCTION}

Neuropathic pain is a common debilitating condition in clinical practice. The International Association for the Study of Pain defines neuropathic pain as 'pain caused by a lesion or disease of the somatosensory nervous system'. Central neuropathic pain is defined as 'pain caused by a lesion or disease of the central somatosensory nervous system', and peripheral neuropathic pain is defined as 'pain caused by a lesion or disease of the peripheral somatosensory nervous system. ${ }^{1}$

Neuropathic pain is not a single disease entity, but a conglomeration of different diseases and lesions, 
manifesting as an array of symptoms and signs. Treatment options include managing underlying pathophysiology and use of antidepressants, anticonvulsant agents, capsaicin, membrane stabilizers and analgesics. Gabapentin and Amitriptyline are among the most commonly prescribed drugs for neuropathic pain. Acute administration of these drugs exposes the patients to unwanted side effects which may lead to discontinuation of treatment and significantly impair quality of life. ${ }^{2,3}$ There is limited longitudinal data available for course of ADR developing with these drugs. Hence, the present study was conducted to analyze the safety profile of gabapentin and amitriptyline in a tertiary care hospital.

\section{METHODS}

A prospective, open-label, observational study was conducted over a period of one year (January 2015 to December 2015) on patients who received Pregabalin or Amitriptyline for control of neuropathic pain as prescribed by physician or orthopedic surgeon at All India Institute of Medical Sciences, Rishikesh, Uttarakhand.

Newly diagnosed patients as well as patients who were receiving either Pregabalin or Amitriptyline were included in the present study. Patients were interviewed for adverse drug reactions using a pre-tested semi-structured questionnaire. Patient records were also checked for appropriate clinical findings and laboratory investigations. Any adverse clinical outcome / laboratory report during use of these drugs was noted on a customized case record form. Patients were screened for adverse drug reactions during the entire period of the study by trained staff deputed in Out-Patient Departments of Orthopaedics and General Medicine. The decision of clinician regarding continuation or discontinuation of drugs was not influenced by the process of data collection. The decision of physicians was considered as final.

Sample size was calculated to be 300 to generate a meaningful information. All patients reporting to medicine and orthopedics OPD who were started on pregabalin or amitriptyline were screened initially for the study. They were recruited in the study after obtaining written informed consent. Data of patients with a minimum of one follow-up visit was included in the analysis.

Statistical analysis was done using SPSS and Stata software. Appropriate measures of central tendency were used to describe demographic and clinical parameters. Total duration of exposure was described in terms of number of patient-days on drug therapy. Severity of ADR was described using ordinal scale. Time course of ADR was described in terms of days. No comparison was made with any other agent.

\section{RESULTS}

The present study was conducted on 317 patients diagnosed with neuropathic pain and were on treatment with the study drugs. Mean age of patients was $48( \pm 14.01)$ years. Majority of the patients were females $(70.6 \%)$.

Average number of drugs consumed by the patient during the follow up period was 3.2, 2.8 and 1.5 in the three study visits. Average duration of treatment for the patients was 14.3 days. The mean exposure of the patients to the drugs was $3568.6 \mathrm{mg}$ during the course of their treatment.

Most common underlying etiology for the chronic neuropathic pain were Diabetes mellitus $(47.1 \%)$ followed by post traumatic $(23.1 \%)$ cancer $(19.6 \%)$, demyelinating diseases $(4.3 \%)$. Herpes zoster $(3.5 \%)$ and poststroke (2.4\%) painful neuropathy were least common cause among the study populations.

A total of 276 ADRs were reported during the study period out of which 128 were associated with Pregabalin and 148 were seen with Amitriptyline.

The details about each drug group and related ADR are given below:

\section{Pregabalin}

A total of 144 patients were taking Pregabalin for neuropathic pain. Gender distribution showed 52 (36.2\%) were male and $92(63.8 \%)$ were females. Mean of age of patients during the study was $52.3( \pm 12.28)$ years.

Average number of drugs which were taken by the patients at visit one was 3.18 whereas on visit 2 and visit 3 was 3.09 and 1.85 respectively. Average number of drugs consumed during the study period was 2.72. Pregabalin was prescribed at a dose of $75 \mathrm{mg}$ once a day at bedtime. Average duration of treatment was 23.95 days with a minimum of 5 days to a maximum of 90 days per patient. Dose modification was required in only one patient where it was increased to two tablets. The study drug was stopped in $31(21.5 \%)$ patients due to ADRs. In only 1 patient the drug was started again. Total drug exposure of individual patients was calculated by multiplying dose, frequency and duration of treatment. It showed a mean of $6315.6 \mathrm{mg}$ per person with a range of 300 to 27000 .

Among 128 ADRs reported due to Pregabalin, dryness of mouth $(34,23.6 \%)$ was the most common followed by Central nervous system reactions like dizziness (21, $14.6 \%)$, sedation $(17,11.8 \%)$ and memory impairment $(7$, $4.8 \%$ ). Blurred vision and tingling sensation were seen in 3 patients each. Insomnia, restlessness, headache and lack of coordination were seen in 1 patient each. Gastrointestinal symptoms like constipation $(5,3.9 \%)$, GI irritation $(4,2.78 \%)$ and a loss of appetite $(2,1.4 \%)$ were also seen. Nausea, abdominal pain and bitterness of mouth were seen in one patient each. Among the musculoskeletal system, weakness and fatigue constituted 7 (4.8\%) ADRs each. (Table 1) 
Table 1: List of ADR and total drug exposure delete.

\begin{tabular}{|c|c|c|c|c|}
\hline \multirow{2}{*}{$\begin{array}{l}\text { I need to be very } \\
\text { strengthened } \\
\text { Adverse drug } \\
\text { reaction }\end{array}$} & \multicolumn{2}{|l|}{ Pregabalin } & \multicolumn{2}{|l|}{ Amitriptyline } \\
\hline & $\begin{array}{l}\text { Number of ADR } \\
\text { N }(\%)\end{array}$ & $\begin{array}{l}\text { Total drug } \\
\text { exposure }\end{array}$ & $\begin{array}{l}\text { Number of ADR } \\
\text { N }(\%)\end{array}$ & $\begin{array}{l}\text { Total drug } \\
\text { exposure }\end{array}$ \\
\hline $\begin{array}{l}\text { Dryness of } \\
\text { mouth }\end{array}$ & $34(26.5)$ & 5591.91 & $35(20.2)$ & 895 \\
\hline Sedation & $17(13.2)$ & 5885.3 & $31(17.9)$ & 665.80 \\
\hline Dizziness & $21(16.4)$ & 6878.57 & $22(12.7)$ & 978.18 \\
\hline $\begin{array}{l}\text { Lack of } \\
\text { coordination }\end{array}$ & $1(0.8)$ & 1500 & $8(4.6)$ & 572.5 \\
\hline Weakness & $7(5.4)$ & 6206.83 & $4(2.3)$ & 517.5 \\
\hline Fatigue & $7(5.5)$ & 7800 & $6(3.4)$ & 733.33 \\
\hline $\begin{array}{l}\text { Memory } \\
\text { impairment }\end{array}$ & $7(5.4)$ & 3942.85 & $4(2.7)$ & 680 \\
\hline Facial edema & $2(1.5)$ & 6120 & $6(3.4)$ & 730 \\
\hline Constipation & $5(3.9)$ & 9300 & $4(2.3)$ & 650 \\
\hline Gastric irritation & $4(3.1)$ & 4218 & $2(1.1)$ & 1100 \\
\hline Abdominal pain & $1(0.7)$ & 4600 & 0 & 0 \\
\hline Nausea & $1(0.7)$ & 4500 & $3(1.7)$ & 400 \\
\hline Loose motion & $1(0.7)$ & 1125 & 0 & 0 \\
\hline Vomiting & 0 & 0 & $1(0.5)$ & 280 \\
\hline Restlessness & $1(0.7)$ & 3000 & $2(1.1)$ & 800 \\
\hline Insomnia & $1(0.7)$ & 3000 & $2(1.1)$ & 1200 \\
\hline Headache & $1(0.7)$ & 2250 & $2(1.1)$ & 600 \\
\hline Itching & 0 & 0 & $2(1.1)$ & 800 \\
\hline Pedal edema & 0 & 0 & $2(1.1)$ & 540 \\
\hline Palpitation & 0 & 0 & $2(1.1)$ & 1100 \\
\hline Breathlessness & 0 & 0 & $2(1.1)$ & 290 \\
\hline BP elevation & 0 & 0 & $2(1.1)$ & 100 \\
\hline Fever & 0 & 0 & $1(0.5)$ & 280 \\
\hline Weigh loss & $1(0.7)$ & 9000 & $1(0.5)$ & 6000 \\
\hline Weight gain & $1(0.7)$ & 4500 & $1(0.5)$ & 840 \\
\hline $\begin{array}{l}\text { Bitterness of } \\
\text { mouth }\end{array}$ & $1(0.7)$ & 9000 & 0 & 0 \\
\hline $\begin{array}{l}\text { Increased } \\
\text { urination }\end{array}$ & $1(0.7)$ & 2100 & 0 & 0 \\
\hline Hypoglycemia & $1(0.7)$ & 1050 & 0 & 0 \\
\hline
\end{tabular}

Causality assessment done by the investigator for the ADRs showed Probable in 118 cases and Possible in 10 cases. (Figure 1)

ADRs associated with Pregabalin showed mild severity $(87,68 \%)$, moderate $(40,31.2 \%)$ and severe $(1,0.7 \%)$ cases. (Figure 2)

\section{Amitriptyline}

A total of 173 patients were taking Amitriptyline for their neuropathic pain out of which $41(23.6 \%)$ were males and
$132(76.31 \%)$ were females. Mean of age of patients who had ADRs was $44.37( \pm 14.35)$ years.

Average number of drugs which were taken by the patients at visit one was 3.23 (range -1 to 7 ), visit 2 was 2.57 and visit 3 was 1.2. Average number of drugs consumed during the study period was 2.33 . Average duration of treatment was 19.86 days. The drug was taken at a dose of $10 \mathrm{mg}$ in 161 patients and $25 \mathrm{mg}$ in 12 patients. It was prescribed once at bedtime for 158 patients and twice daily in 3 patients. Dose modification was required only for 5 patients. Dosage in 4 patients had to be increased from 10 
$\mathrm{mg}$ to $25 \mathrm{mg}$ and had to be reduced to $10 \mathrm{mg}$ in one patient. Drug was stopped in 55 patients.

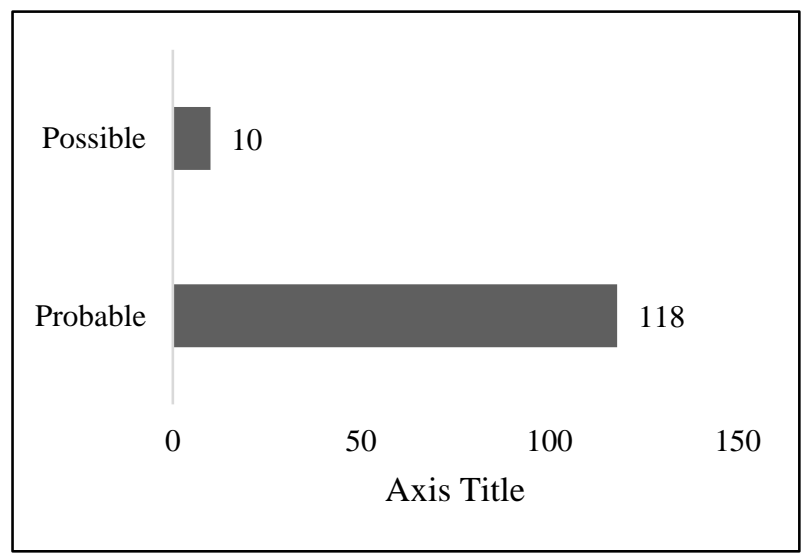

Figure 1: Causality assessment of ADR from Pregabalin.

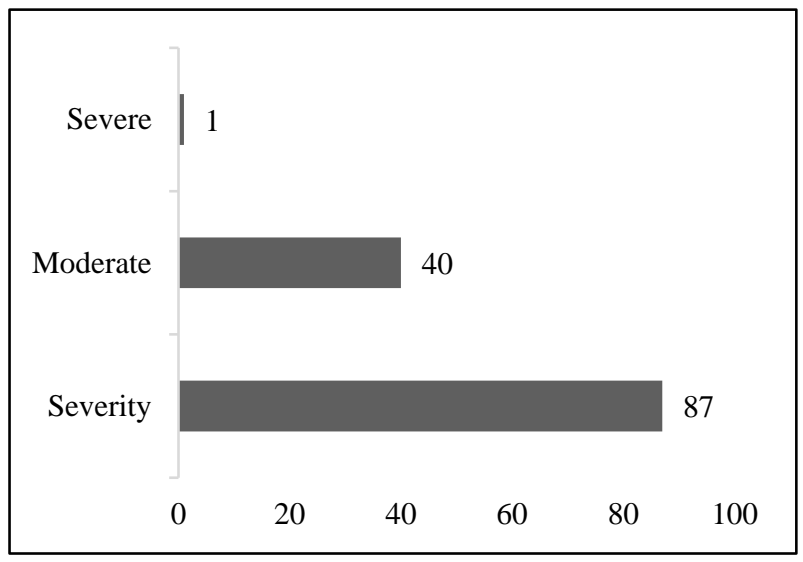

Figure 2: Severity assessment of ADR from Pregabalin.

Total drug exposure of individual patient was calculated by multiplying dose, frequency and duration of treatment. It showed a mean of $821.6 \mathrm{mg} /$ person with a range of 70 to 6000 .

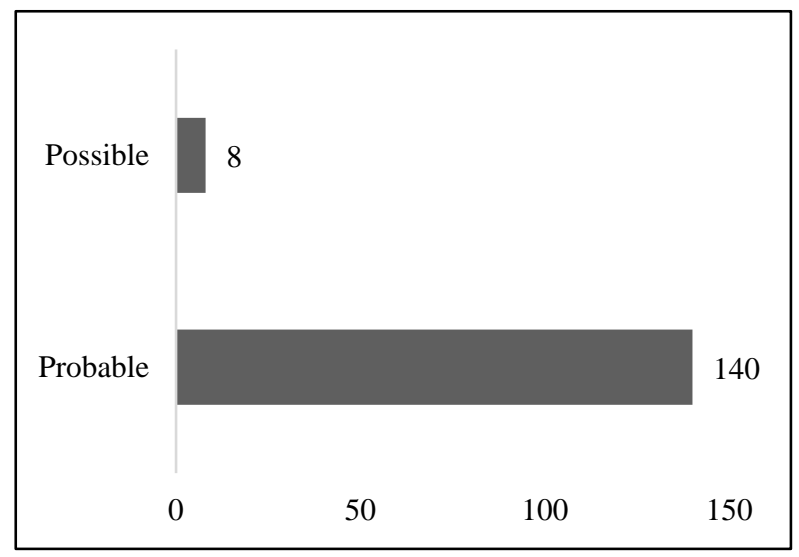

Figure 3: Causality assessment of ADR from Amitriptyline.

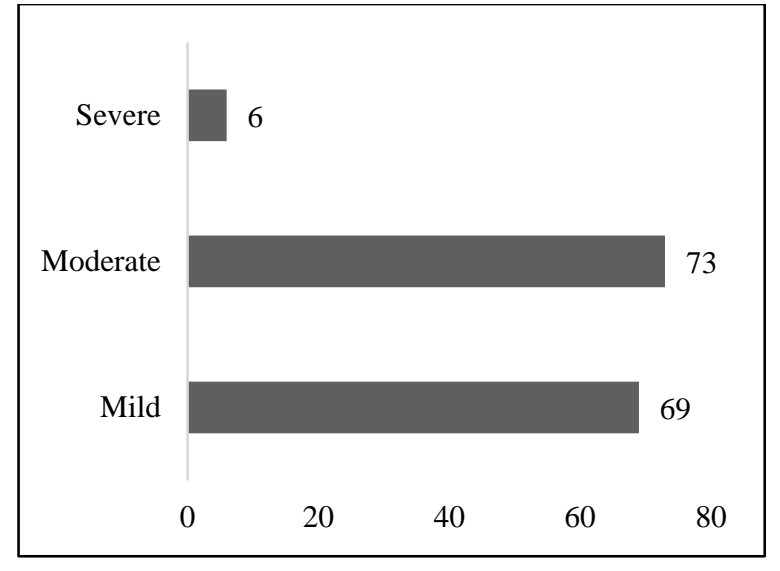

Figure 4: Causality assessment of ADR from Amitriptyline.

Out of 148 ADRs reported with patients on Amitriptyline, dryness of mouth $(35,20.2 \%)$ constituted the major autonomic ADR. CNS symptoms like sedation (31,17.9\%) and dizziness $(22,12.7 \%)$ constituted the majority of the symptoms. ADR associated with lack of coordination was seen in $8(4.6 \%)$ patients, memory impairment in in 4 $(2.7 \%)$ and headache and insomnia in 2 patients each. Restlessness was reported in 2 patients. Facial edema and fatigue were reported in $6(3.4 \%)$ patients each. Gastrointestinal symptoms like constipation (4), nausea (3), GI irritation (2) and vomiting (1) were reported. Breathlessness, palpitation and itching were seen 2 patients each. One patient in the study reported elevation in blood pressure (Table 1).

Causality assessment done for the ADRs showed Probable in 140 cases and Possible in 8 cases. Since re-challenge was not done in any patient Certainty of ADR could not be assessed in any ADRs. (Figure 3)

Severity scale showed ADR were mild in $69(46.6 \%)$ cases, moderate in $73(49.3 \%)$ cases and severe in $6(4 \%)$ cases. (Figure 4)

On analysis weak positive correlation $(\mathrm{R}=0.273)$ was observed between the number of ADRs and the total drug exposure per patients in the Pregabalin treated group whereas a weak negative correlation $(R=-0.623)$ was observed in the Amitriptyline treated group.

\section{DISCUSSION}

The present study was conducted on 317 patients diagnosed with neuropathic pain who were on treatment with the study drugs. Mean age of patients was $48( \pm 14.0)$ years. Gender distribution showed $29.3 \%$ were males and $70.6 \%$ were females. A study by Chakrabarty et al showed $71 \%$ male patients with a similar mean age of patients $(48.61 \%)^{4}$

A multi-centric study conducted by Kamble et al had a similar number of patient data (281). The participants of 
the study were taken from orthopedic surgeons, internal medicine specialists and general practitioners similar to our study. 5

Average number of drugs taken by all the patients during the follow up period was 3.2, 2.8 and 1.5 in the three study visits. An average of 2.5 drugs were taken by each patient during the course of study. An observational study done by Jena et al in Odisha showed polytherapy was practiced in $89 \%$ of patients taking treatment for neuropathic pain. Average number of drugs prescribed was $2.88 .^{6}$

Average duration of treatment for the patients were 14.3 days. Average number of concomitant drugs taken with Pregabalin during the study period was 2.7 and 2.3 with Amitriptyline.

Most commonly used dose was $75 \mathrm{mg}$ bedtime for Pregabalin and $10 \mathrm{mg}$ bedtime for Amitriptyline group. Similar results were seen by Kamble et al wherein $71.01 \%$ of the caregivers-initiated amitriptyline in the dose ranging from $5-10 \mathrm{mg}$ per day and $78.3 \%$ of the caregivers continued using amitriptyline at a daily maintenance dose of $5-10 \mathrm{mg} /$ day. Regarding pregabalin $86.18 \%$ of the caregivers initiated pregabalin in a dose ranging from 50$75 \mathrm{mg}$ per day and $87.79 \%$ of the caregivers continued using pregabalin at a daily maintenance dose of 50-75 mg/day. ${ }^{5}$

Dose change was required in only $5(2.8 \%)$ patients in Amitriptyline group and $1(0.69 \%)$ patient in Pregabalin group. Dose change was required in $18.9 \%$ and $12.1 \%$ patients in the Amitriptyline and Pregabalin group respectively in a study by Kamble et al.

Drug discontinuation is a common problem in patients of neuropathic pain. Our study had shown that $31(21.5 \%)$ patients had to stop Pregabalin due to ADRs. In Amitriptyline group 55 (31.8\%) patients halted the drug use. The study findings are similar to data reported by Rickter et al and Backonja et al where discontinuation of analgesics was seen in up to 20 to $40 \%$ patients. ${ }^{7,8}$

Average duration of treatment was 19.8 and 23.95 in Amitriptyline and Pregabalin group respectively. The mean exposure of the patients to the drugs was $3568.6 \mathrm{mg}$ during the course of their treatment.

\section{Adverse drug reactions}

A total of 276 ADRs were reported during the study period out of which 128 were associated with Pregabalin and 148 were seen with Amitriptyline. A study conducted by Jena et al showed similar results where Tricyclic antidepressants (Amitriptyline) constituted $58 \%$ of all ADRs.

Our study had showed incidence of sedation and dizziness as $38(29.6 \%)$ and $53(35.8 \%)$ in patients receiving Pregabalin and Amitriptyline respectively. Dryness of mouth was seen in 23.6 and $20.3 \%$ in both the drugs. A study conducted by Kamble et al showed that predominant ADR seen from patients receiving Pregabalin was sedation and drowsiness $(53.6 \%)$ followed by giddiness/ dizziness (20\%) cases. Dryness of mouth was present in $1.88 \%$ cases. Patients receiving Amitriptyline had sedation/drowsiness in $48.7 \%$ ADRs. It was followed by dry mouth in $16.05 \%$ cases. Giddiness was present in $6.5 \%$ of cases in these patients. The study findings are similar to our study. ${ }^{6}$

Our study had shown that neuropsychiatric ADRs are most common with Pregabalin [48 ADR (37.5\%)]. There were no reports of death in our study. A French database analysis also showed similar results with the use of Pregabalin (35.2 $\%$ ) followed by Gabapentin (29.1\%). There were reports of 22 deaths from 1331 case reports on the study which was conducted over 14 years. Our study was done for a short period of 6 months. ${ }^{9}$ A similar study showed that sleep disturbance $(17.1 \%)$ followed by dizziness $(5.6 \%)$ were most commonly reported adverse effects with Amitriptyline whereas dizziness (16.7\%) was most commonly seen with Pregabalin. Sleep disorder (5.6\%) and dyspepsia $(2.8 \%)$ were the remaining. ${ }^{10}$

A study by Shankar et al also showed CNS ADRs as most common with predominant day time sleepiness as the predominant ADR in both the drugs $(31.4 \%$ with Amitriptyline and $75 \%$ with Pregabalin). ${ }^{11}$ A recent study by Chakrabarty et in 147 patients showed sedation was the most common ADR accounting for $42.7 \%$ of ADRs. Amitriptyline group patients suffered from maximum ADRs (44.9\%) in the study. $82 \%$ ADR were probable in the study. There was no definite association. All ADRs were mild in severity in the study.

Causality assessment showed Possible (10, 7.8\%) and Probable $(118,92.1 \%)$ with Pregabalin. No definite association was seen. Amitriptyline showed Possible (8, $5.4 \%)$ and Probable $(140,94.6 \%)$ cases. A study by Arvinth et al showed similar results where most ADR were of Probable (78\%) followed by possible (22\%) with Pregabalin. No definite association could be established in their study. Chakrabarty et al also depicted similar result with Probable (83\%) as most common causality. ${ }^{4}$

Seriousness with Pregabalin showed mild in $87(68 \%)$, moderate in $40(31.25 \%)$ cases. One patient $(0.78 \%)$ showed severe ADR. Amitriptyline ADRs were mild in 69 $(46.6 \%)$ cases, moderate in $73(49.3 \%)$ cases and severe in $6(4 \%)$ cases. A study by Chakraborty et al also showed similar results where most ADRs were of mild intensity with Pregabalin. ${ }^{4}$

Adverse reactions to analgesics in neuropathic pain is a common problem. Chronic administration of Pregabalin and Amitriptyline were frequent causes of ADRs. The present study provides an understanding of the distribution of ADRs among patients of neuropathic pain in Uttarakhand region. The limitations of this research include the short duration of the study period, the limited sample size. Causality and severity assessment were done 
by the investigator at the site and then analyzed by the other authors. Since polypharmacy was practiced in most patients it was difficult to establish a causal relationship with the ADRs.

\section{Limitations of the study}

The present studies explored the adverse drug reactions of Amitriptyline and Gabapentin in Neuropathic pain. Most patients in the study were receiving multiple medications due to their existing comorbidities making the causality assessment difficult. Most ADRs reported were mild in nature and did not require discontinuation or withholding the study drugs. Moreover, very limited patients were rechallenged with the suspected offending drugs.

\section{CONCLUSION}

Neuropathic pain is commonly treated by Pregabalin and Amitriptyline, both of which have similar efficacy. Safety profile of Pregabalin was better than Amitriptyline in the present study. The study findings must be replicated in larger patient population and for a prolonged duration for better understanding of the pattern of adverse drug reactions.

\section{Funding: No funding sources}

Conflict of interest: None declared

Ethical approval: The study was approved by the Institutional Ethics Committee

\section{REFERENCES}

1. International Association for the Study of Pain (2007) IASP taxonomy. Available at https://www.iasppain.org/Education/Content.aspx?ItemNumber $=1698$ \#Neuropathicpain. Accessed on 10 ${ }^{\text {th }}$ November, 2019.

2. Backonja M, Glanzman RL. Gabapentin dosing for neuropathic pain: evidence from randomized, placebocontrolled clinical trials. Clin Ther. 2003;25(1):81104.

3. Moore RA, Derry S, Aldington D, Cole P, Wiffen PJ. Amitriptyline for neuropathic pain in adults. Cochrane Database Syst Rev. 2015;2015(7):CD008242.

4. Chakrabarty S, Biswas S, Maiti T, Das A, Mandal A, Banerjee P. Pregabalin and amitriptyline as monotherapy or as low-dose combination in patients of neuropathic pain: A randomized, controlled trial to evaluate efficacy and safety in an Eastern India teaching hospital. Ann Indian Acad Neurol. 2019;22:437-41.

5. Kamble SV, Motlekar SA, D'souza LL, Kudrigikar VN, Rao SE. Low doses of amitriptyline, pregabalin, and gabapentin are preferred for management of neuropathic pain in India: is there a need for revisiting dosing recommendations?. Korean J Pain. 2017;30(3):183-91.

6. Jena SS, Jena M, Patro N, Mishra S, Panda M, Dash M. Patterns of prescription and adr monitoring of drugs in the management of neuropathic pain in a tertiary care teaching hospital. International Journal of Pharmacy and Pharmaceutical Sciences. 2006;10(1):246-51.

7. Relief of painful diabetic peripheral neuropathy with pregabalin: a randomized, placebo-controlled trial. Richter RW, Portenoy R, Sharma U, Lamoreaux L, Bockbrader H, Knapp LE J Pain. 2005;6(4):253-60.

8. Backonja M, Glanzman RL. Gabapentin dosing for neuropathic pain: evidence from randomized, placebocontrolled clinical trials. Clin Ther. 2003; 25(1):81104.

9. Fuzier R, Serres I, Guitton E, Lapeyre-Mestre M, Montastruc JL. French Network of Pharmacovigilance Centres. Adverse drug reactions to gabapentin and pregabalin: a review of the French pharmacovigilance database. Drug Saf. 2013;36(1):55-62.

10. Acet G, Kaya A, Akturk S, Akgol G. A comparison of the effectiveness of amitriptilin and pregabalin treatment in fibromyalgia patients. North Clin Istanb. 2017;4(2):151-59.

11. Shaknar V, Oomen O, Thomas A. Efficacy, Safety and Cost Effectiveness of Amitriptyline and Pregabalin in Patients with Diabetic Peripheral Neuropathy. Indian J Pharm Sci. 2017;79(4):646-50.

12. Arvinth A, Muthiah NS, Suganya E, Susshmitha R, Sowmya P. Evaluation of adverse drug reactions of gabapentin to pregabalin in patients of painful diabetic peripheral neuropathy. J Chem Pharm Res. 2016;8(7):540-43.

Cite this article as: Shukla S, Bandyopadhyay A, Kumar S, Vardhan G, Goel B, Choudhary C et al. Painful neuropathy: comparative observational analysis of safety profile of pregabalin and amitriptyline. Int J Basic Clin Pharmacol 2021;10:824-9. 